\title{
Hepatitis C-associated hepatocellular carcinomas in non-cirrhotic livers
}

\author{
Matthew M Yeh ${ }^{1}$, Hubert Darius-J Daniel ${ }^{2}$ and Michael Torbenson ${ }^{2}$ \\ ${ }^{1}$ Department of Pathology, University of Washington School of Medicine, Seattle, WA, USA and \\ ${ }^{2}$ Department of Pathology, Johns Hopkins University School of Medicine, Baltimore, MD, USA
}

\begin{abstract}
Chronic hepatitis C viral infection can lead to cirrhosis and hepatocellular carcinoma. It is generally believed that hepatitis $\mathrm{C}$ infection is not oncogeneic per se, but that the presence of cirrhosis determines the increased risk for hepatocellular carcinoma. However, a search of surgical pathology files from two large tertiary care centers for the years 2001-2008 identified a total of 18 hepatocellular carcinomas in non-cirrhotic livers with chronic hepatitis $\mathrm{C}$ infection. In six cases the background livers showed bridging fibrosis, while the remainder showed lower stages of fibrosis. Cases were negative for clinical and serological evidence of hepatitis B co-infection, and occult hepatitis B test was negative by PCR of formalin-fixed, paraffin embedded tissues. The tumors were also negative for TP53, exon 7, codon 249 mutations, a characteristic mutation strongly linked to aflatoxin exposure. The hepatocellular carcinomas had typical histology with no enrichment for unusual growth patterns or histological features. Among all resected hepatocellular carcinomas in non-cirrhotic livers over this time period, the prevalence of $16 \%$ with HCV infection was significantly greater than that expected by chance. In conclusion, these results demonstrate that hepatocellular carcinomas can arise in livers chronically infected with hepatitis $\mathrm{C}$ but without cirrhosis. These findings raise the possibility that in some cases hepatitis C infection and inflammation can be directly oncogeneic. It is also possible that established cirrhosis may have regressed in some cases. Regardless of the mechanism, these findings highlight an important and previously under-recognized risk for hepatocellular carcinoma in HCV-infected individuals who do not have cirrhosis. Modern Pathology (2010) 23, 276-283; doi:10.1038/modpathol.2009.174; published online 20 November 2009
\end{abstract}

Keywords: hepatitis C virus; hepatocellular carcinoma; non-cirrhotic liver

Hepatocellular carcinoma is one of the most common malignant neoplasms in the world and has increased in numbers in the United States over the past two decades. ${ }^{1}$ Although many of the specific etiologies that lead to hepatocellular carcinoma are well known, the underlying molecular mechanisms leading to hepatocarcinogenesis remain incompletely defined. Nevertheless, cirrhosis from any cause remains one of the strongest known risk factors for hepatocellular carcinoma. Despite this fact, hepatocellular carcinoma may develop in non-cirrhotic livers in some individuals. In particular, hepatitis B virus (HBV) infection has been identified as a cause of hepatocellular carcinoma in the non-cirrhotic liver and HBV can be directly oncogenic, leading to hepatocellular carcinoma through integration of the

Correspondence: Dr MM Yeh, MD, PhD, Department of Pathology, University of Washington School of Medicine, 1959 NE Pacific Street, NE140D, Box 356100, Seattle, WA 98195, USA.

E-mail: myeh@u.washington.edu

Received 18 June 2009; revised 16 September 2009; accepted 21 September 2009; published online 20 November 2009 viral genome into the host genome. ${ }^{2}$ In addition, the $\mathrm{X}$ protein of HBV is a potent transactivator that can interact with p53, interfering with its tumor-suppressor activity. ${ }^{3}$ In part because of these properties of $\mathrm{HBV}$, liver cirrhosis in $\mathrm{HBV}$-infected patients is not a prerequisite for hepatocarcinogenesis. In contrast, it is generally believed that the presence of cirrhosis determines the increased risk for hepatocellular carcinoma in individuals with chronic hepatitis C viral (HCV) infection. ${ }^{4-6}$ To date there is very little data on HCC arising in HCV infected, but non-cirrhotic, livers. The aims of this study are to characterize the clinical, pathologic and molecular features of hepatocellular carcinomas arising in non-cirrhotic livers of $\mathrm{HCV}$-infected individuals.

\section{Materials and methods}

Case Selection

The surgical pathology files at two tertiary medical centers from January 1, 2001, to July 1, 2008, were 
searched for HCV-related hepatocellular carcinomas that arose in non-cirrhotic livers and were surgically resected with intent to cure. Fibrolamellar carcinomas were excluded. Medical records were examined for HCV and HBV histories, including serological and virology tests. Due to the multi-center and retrospective nature of this study, the testing platforms differed among the patients. Chronic hepatitis C infection was defined as presence of hepatitis $\mathrm{C}$ viral RNA in the blood as detected by quantitative or qualitative PCR assays. In some referral cases, actual laboratory results were not available and clinical notes reporting HCV positivity were accepted for study inclusion. Serum testing for $\alpha$-fetoprotein (AFP), when available, was recorded as the highest value available within the 6 months prior to surgical resection.

In the general population, most hepatocellular carcinomas arise in cirrhotic livers. However, approximately $15-20 \%$ of hepatocellular carcinoma are reported to arise in non-cirrhotic livers. ${ }^{7}$ In addition, $1.6 \%$ of the total US population have antibodies to $\mathrm{HCV}^{8}{ }^{8}$ with the highest prevalence within the 40- to 49-year age group, which has a prevalence of $4.3 \%$. Thus, some co-occurrence of HCV infection and hepatocellular carcinoma in noncirrhotic livers is expected to occur by chance. To investigate this possibility further, the total number of cases of all hepatocellular carcinomas arising in non-cirrhotic liver was determined to see if the prevalence of HCV-related hepatocellular carcinomas in non-cirrhotic livers was greater than that expected by chance. The prevalence of HCV-related hepatocellular carcinomas was compared with that of the overall US population (1.6\%) and, as the most conservative approach, was also compared with the segment of the US population with the highest prevalence $(4.3 \%)$.

\section{Molecular Analysis}

All identified cases had available paraffin-embedded tissues for analysis. To exclude hepatitis B infection, including occult hepatitis B, genomic DNA was extracted from paraffin blocks of the resected tumors and non-tumorous tissues. Sections of $10 \mu \mathrm{m}$ thickness were microdissected and digested with proteinase- $\mathrm{K}, 1 \mathrm{mg} / \mathrm{ml}$ at $56{ }^{\circ} \mathrm{C}$ for $16 \mathrm{~h}$ and PCR was performed with primers directed against a region of the HBV-surface gene. To evaluate for CTNNB1 ( $\beta$-catenin) mutations, the same DNA extracts were amplified with primers directed against exon 3 of the $\beta$-catenin gene as previously described. ${ }^{9}$ To exclude aflatoxin exposure, exon 7 of the TP53 gene was amplified and sequenced using primers as previously reported..$^{10}$ Aflatoxin exposure induces a characteristic G-to-T transversion at codon 249. The amplicons were purified and directly sequenced in the forward and reverse directions.

\section{Histological Analysis}

The pathological features were reviewed by two pathologists (MM Yeh and M Torbenson). Routine H\&E stains and trichrome stains were examined. The background inflammation and fibrosis in the non-neoplastic liver was graded and staged using the modified Histologic Activity Index, or 'Ishak' system, with inflammation graded on a scale of 0-18 and fibrosis on a scale of 0-6. Pericellular fibrosis was also separately noted when present. Steatosis was scored as $0 \quad(0-4 \%$ steatosis $), \quad 1 \quad(5-30 \%$ steatosis), 2 (31-60\% steatosis) and 3 (greater than $60 \%$ steatosis). The presence of steatohepatitis was also noted when appropriate. The tumor differentiation was graded as per the Edmonson-Steiner (ES) grading system ${ }^{11}$ on a scale of $0-4$. Tumors were staged according to the TNM staging system. In addition, the tumor growth pattern was evaluated as per the WHO classification schema. ${ }^{12}$

\section{Results}

\section{Clinical and Laboratory Findings}

During the study period, there were total 51 HCC in non-cirrhotic livers from Johns Hopkins. Underlying liver disease included unknown $(n=32)$, chronic HCV $(n=9)$, chronic HBV $(n=5)$ infection, and associated with hepatic adenomas $(n=5)$. There were total 63 HCC in non-cirrhotic livers from the University of Washington Medical Center and underlying liver diseases included unknown $(n=45)$, chronic HCV $(n=9)$ and chronic HBV infection $(n=9)$.

The study then focused on the 18 hepatocellular carcinomas that arose in non-cirrhotic livers of individuals with chronic HCV infection (Table 1). The average age at resection was $58 \pm 6.8$ (mean \pm s.d.) years. There were 14 men and four women, including nine Whites, five Blacks, two Asians and two Egyptians. Only a single individual had additional identifiable causes of liver disease (iron overload and significant alcohol use).

In the 11 patients with available genotype information (Table 1), no enrichment for unusual HCV genotypes was observed: genotype $1 \mathrm{~A}(n=3)$, 1B $(n=3), 2 \mathrm{~B}(n=2), 3 \mathrm{~A}(n=1)$ and $4(n=2)$. Hepatitis $\mathrm{C}$ viral loads averaged $6.4 \mathrm{log} \mathrm{IU} / \mathrm{ml}$ in the 11 cases with available information. Among the 16 cases with available AFP information, only three had serum AFP levels greater than $30 \mathrm{ng} / \mathrm{ml}: 5188 \mathrm{ng} / \mathrm{ml}$, $2329 \mathrm{ng} / \mathrm{ml}$ and $2303 \mathrm{ng} / \mathrm{ml}$.

Next analysis was performed to investigate whether the frequency of HCV infection in noncirrhotic livers with hepatocellular carcinoma was higher than the baseline frequency in the general population (Figure 1). Both the individual and the combined prevalence of $16 \%$ (95\% confidence interval, $8-22 \%$ ) were found to be higher than that expected by chance, (all $P<0.01, \chi^{2}$-test). Repeat 
Table 1 Clinical and laboratory findings

\begin{tabular}{|c|c|c|c|c|c|c|c|c|}
\hline Individual & Gender & Age & Race & $\begin{array}{l}\text { HCV } \\
\text { genotype }\end{array}$ & HCV viral load & $A F P(n g / m l)$ & Presentation & Outcome \\
\hline 1 & M & 66 & Egyptian & $4 \mathrm{~A}$ & NA & NA & Found on ultrasound screen & $\begin{array}{l}\text { NED at } 17 \text { months; lost to follow- } \\
\text { up }\end{array}$ \\
\hline $2^{\mathrm{a}}$ & $\mathrm{F}$ & 66 & Black & NA & NA & 5 & Pruritis & Death at 20 months after surgery \\
\hline 3 & M & 58 & Black & $1 \mathrm{~A}$ & NA & 6 & RUQ pain & NED at 23 months \\
\hline 4 & $\mathrm{M}$ & 45 & White & $1 \mathrm{~A}$ & $6.29 \log$ & 14 & NA & Death at 23 months after surgery \\
\hline 5 & $\mathrm{~F}$ & 62 & Black & $1 \mathrm{~B}$ & $6.81 \log$ & 17 & $\begin{array}{l}\text { Found on ultrasound screen for } \\
\text { follow-up of liver cysts and } \\
\text { mildly elevated AFP }\end{array}$ & Death at 26 months after surgery \\
\hline 6 & $\mathrm{M}$ & 56 & White & $1 \mathrm{~A}$ & $\begin{array}{l}6.86 \log 9 \text { months after } \\
\text { surgery }\end{array}$ & 21 & $\begin{array}{l}\text { Found at the time of liver biopsy } \\
\text { by radiology, biopsy for staging } \\
\text { and grading of HCV }\end{array}$ & NED at 32 months \\
\hline 7 & M & 49 & White & $1 \mathrm{~B}$ & $\begin{array}{l}6.27 \log 13 \text { months } \\
\text { after surgery }\end{array}$ & 5188 & Elevated AFP & $\begin{array}{l}\text { Suspicious lung nodule at } 23 \\
\text { months }\end{array}$ \\
\hline 8 & $\mathrm{~F}$ & 55 & Black & $3 \mathrm{~A}$ & $\begin{array}{l}6.66 \log 28 \text { months } \\
\text { after surgery }\end{array}$ & 11 & Found on imaging screen & NED at 11 months \\
\hline 9 & M & 49 & White & NA & $6.13 \log$ & 2329 & Found on $w / u$ for colon met & Death at 2 months after surgery \\
\hline $10^{\mathrm{a}}$ & $\mathrm{M}$ & 67 & Asian & NA & NA & 2303 & Elevated AFP & Lung metastasis at 30 months \\
\hline $11^{\mathrm{a}}$ & $\mathrm{M}$ & 58 & White & NA & NA & 7.9 & Found on imaging screen (CT) & Recurrence at 5 months \\
\hline 12 & $\mathrm{M}$ & 57 & White & $2 \mathrm{~B}$ & $6.24 \log$ & 27.1 & Found on ultrasound screen & $\begin{array}{l}\text { Multiple residual HCC at } 5 \\
\text { months }\end{array}$ \\
\hline 13 & $\mathrm{~F}$ & 59 & Egyptian & 4 & $6.92 \log$ & 14.1 & RUQ pain and elevated LFT & Recurrent HCC at 20 months \\
\hline 14 & M & 68 & Asian & $1 \mathrm{~B}$ & $5.27 \log$ & 28 & RUQ pain, weight loss & $\begin{array}{l}\text { Recurrent HCC, death at } 24 \\
\text { months after surgery }\end{array}$ \\
\hline 15 & $\mathrm{M}$ & 52 & White & $2 \mathrm{~B}$ & $1.426 \mathrm{e} \mathrm{IU} / \mathrm{ml}$ & $<5$ & Found on imaging screen (CT) & $\begin{array}{l}\text { Recurrent HCC, death at } 48 \\
\text { months after surgery }\end{array}$ \\
\hline $16^{\mathrm{a}}$ & M & 67 & White & NA & NA & NA & $\begin{array}{l}\text { Found on imaging (CT) for chest } \\
\text { pain }\end{array}$ & NED at 3 months \\
\hline 17 & M & 57 & White & NA & $1.900 \mathrm{e} \mathrm{IU} / \mathrm{ml}$ & 22.8 & Found on ultrasound screen & NED at 9 months \\
\hline $18^{\mathrm{a}}$ & M & 60 & Black & NA & NA & 12 & RUQ pain & NED at 9 months \\
\hline
\end{tabular}

Abbreviations: AFP, $\alpha$-fetoprotein; CT, computed tomography; HCC, hepatocellular carcinoma; HCV, hepatitis C virus; NA, not available; NED, no evidence of disease; RUQ, right upper quadrant; w/u, workup; met, metastasis.

${ }^{\mathrm{a}}$ No HCV RNA testing was available for these individuals and diagnosis of chronic HCV is based on the clinical diagnosis in the medical records. 


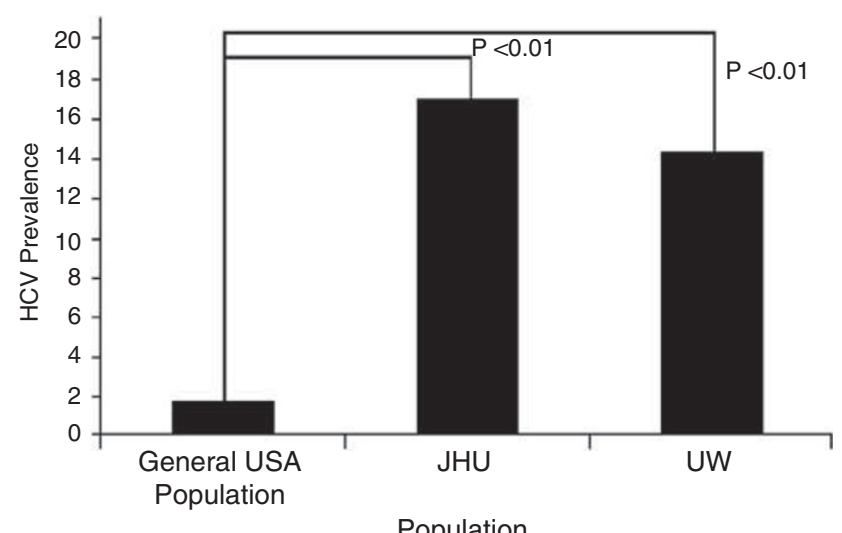

Figure 1 The combined prevalence $(16 \%)$ of HCV in the noncirrhotic livers with hepatocellular carcinoma at two institutes (17\% for JHU (Johns Hopkins University) and 14\% for UW (University of Washington)) is significantly higher than the prevalence of HCV antibodies in the general US population $(1.6 \%)$.

analysis using the peak prevalence of anti-HCV antibodies in the US of $4.3 \%$ for the 40 - to 49 -years time interval remained significantly different than the combined prevalence of $15 \%\left(P=0.004, \chi^{2}\right.$-test $)$.

\section{Pathologic Findings in Background Livers}

Sections of the background non-neoplastic livers were available in all 18 resection specimens. The typical histological features of chronic hepatitis $\mathrm{C}$ were found in all the cases, including mild-tomoderate portal inflammatory infiltrates composed predominantly of mature-appearing lymphocytes, mixed with occasional plasma cells, eosinophils and Kupffer cells (Figure 2a). Lymphoid aggregates eccentrically located in the portal tracts were common. Scattered foci of inflammatory infiltrates were present in the hepatic lobules (Figure 2b), composed predominantly of lymphocytes and Kupffer cells. On trichrome stains, eight cases showed moderate portal fibrosis (Figure 2c), six cases showed bridging fibrosis (Figure 2d) and the remaining livers showed no significant or only minimal fibrosis. None of the cases were histologically cirrhotic.

\section{Tumor Characteristics}

As shown in Table 2, the average tumor size was $5.9 \mathrm{~cm}$ and the tumors were unifocal in nine cases and multifocal in nine cases. Pathological staging of hepatocellular carcinoma ${ }^{13}$ was $\mathrm{T} 1$ in six cases, T2 in eight cases and T3 in four cases. The histology of the tumors (not available for review in one case due to complete tumor necrosis) showed the typical morphology of hepatocellular carcinoma (Figures 2e and $\mathrm{f}$ ). The observed growth patterns were typical of hepatocellular carcinoma and included a pseudoglandular pattern in six cases, solid pattern in nine cases and a mixed pattern in two cases. The hepatocellular carcinomas were classified as Edmonson-Steiner grade-1 in two cases, grade-2 in five cases, grade-3 in seven cases and grade- 4 in three cases, respectively.

\section{Molecular Results}

All cases were negative for HBV DNA in the liver tissues. No mutations were seen in exon 3 of $\beta$-catenin or in exon 7 of TP53.

\section{Discussion}

In the US, approximately 50\% of hepatocellular carcinomas are caused by chronic HCV infection. ${ }^{14}$ The pathogenesis of hepatocellular carcinoma in chronic HCV infection is generally accepted as chronic inflammation and injury, which leads to fibrosis with eventual progression to cirrhosis and subsequent development of hepatocellular carcinoma. ${ }^{15}$ Cirrhosis has generally been considered a prerequisite for HCV-infected livers to develop hepatocellular carcinoma. However, in this study we document the presence of hepatocellular carcinoma arising in non-cirrhotic livers infected with chronic HCV. This represents an important advance in our understanding of the natural history of $\mathrm{HCV}$ infection. The combined prevalence of HCV-positive cases among all resections for hepatocellular carcinoma in non-cirrhotic livers was $16 \%$, significantly higher than the general prevalence of HCV-infected individuals in the US population.

Chronic HBV infection is an important risk factor for hepatocellular carcinoma, and it is well known that cirrhosis is not a prerequisite for the development of hepatocellular carcinoma, especially in Asian and African patients. ${ }^{15}$ Cancers can arise in non-cirrhotic livers largely because HBV DNA is capable of integrating into the host genome and can subsequently cause malignant transformation of hepatocytes. ${ }^{2}$ Furthermore, the HBV X protein has many possible pro-oncogenic properties, including disrupted p53 tumor-suppressor activity, ${ }^{3}$ and this can occur early in the process of tumorigenesis. ${ }^{16}$ In addition, in occult HBV infection, defined as the presence of viral DNA in blood or liver tissues in persons who are HBsAg-negative, ${ }^{9} \mathrm{HBV}$ virus can continue to replicate at low levels, ${ }^{17}$ which could cause persistent inflammation and injury, which may contribute to the formation of hepatocellular carcinoma. In the current study, co-infection with HBV does not appear to have played a role as all cases for HBV DNA in the liver tissue were negative as shown by PCR.

$\mathrm{HCV}$ is an RNA virus that does not integrate into the host genome and the mechanism of HCVassociated hepatocellular carcinoma arising in non-cirrhotic livers is not clear. Several HCV-gene products, including the core, NS3, NS4B and NS5A, 

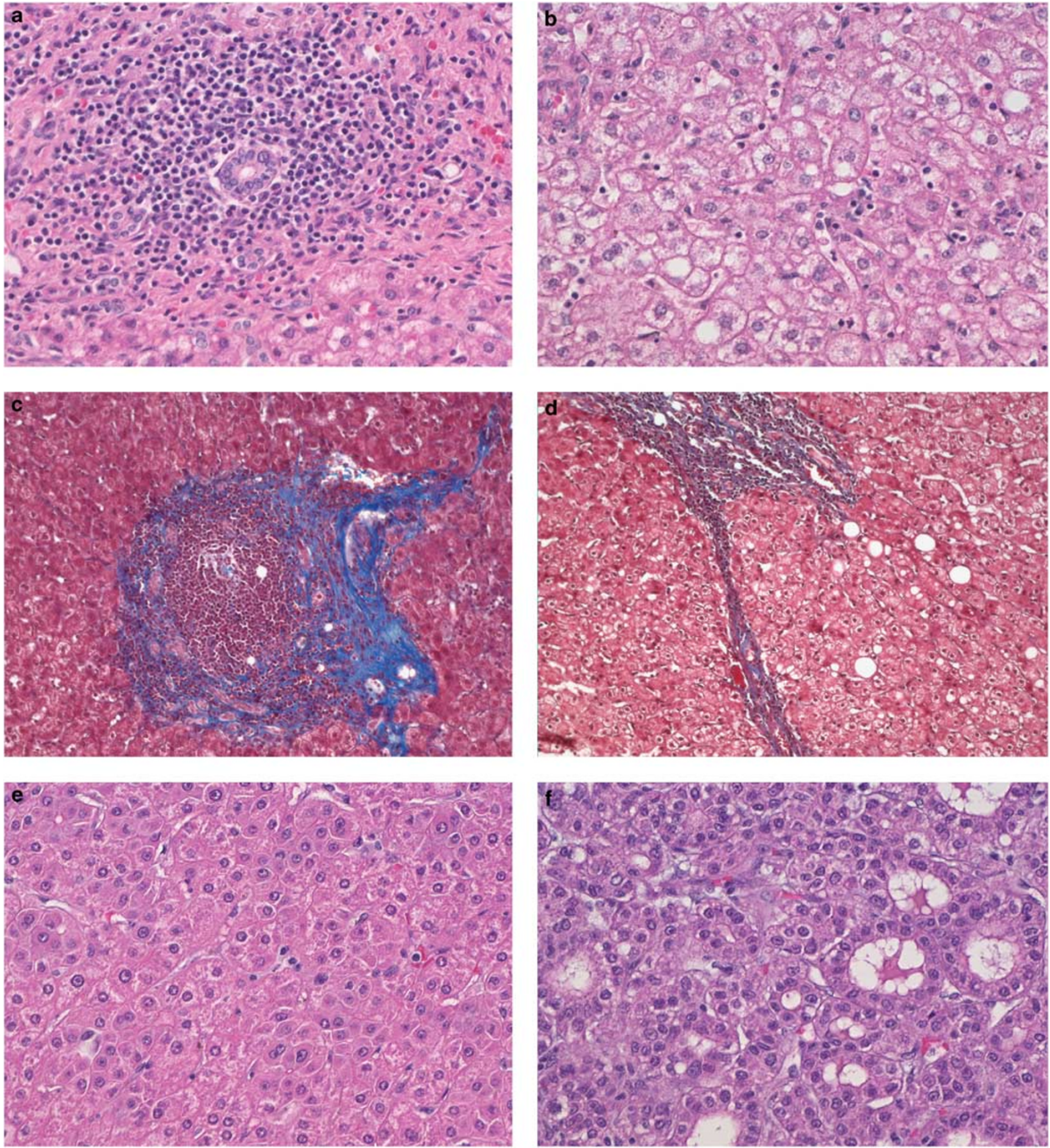

Figure 2 The cases showed the typical histology of chronic hepatitis C, with mild-to-moderate portal inflammatory infiltrates $(\mathbf{a}, \times 250$ original magnification), composed predominantly of mature-appearing lymphocytes mixed with occasional plasma cells, eosinophils and Kupffer cells. Lymphoid aggregates eccentrically located in the portal tracts were common. Scattered foci of inflammatory infiltrates were present in the hepatic lobules, composed predominantly of lymphocytes and Kupffer cells (b, $\times 250)$. Masson trichrome stains showed periportal fibrosis $(\mathbf{c}, \times 40)$ or bridging fibrosis $(\mathbf{d}, \times 40)$. Hepatocellular carcinoma showed the classical histology with thickened trabecular $(\mathbf{e}, \times 100)$ and/or pseudoglandular formation $(\mathbf{f}, \times 100)$.

are capable of malignant transformation of hepatocytes in cell model systems, ${ }^{18}$ and in some individuals this could potentially be sufficient to cause hepatocellular carcinoma. The expression of HCV proteins has also been shown to alter several potentially oncogenic pathways via cell signaling, transcriptional modulation, apoptosis, transformation and translational regulation, and through 
Table 2 Histological findings in the resected livers

\begin{tabular}{|c|c|c|c|c|c|c|c|c|}
\hline Patient & Tumor size $(\mathrm{cm})$ & $\begin{array}{l}\text { Tumor } \\
\text { stage }^{\mathrm{a}}\end{array}$ & $\begin{array}{l}\text { Tumor } \\
\text { grade }^{\mathrm{b}}\end{array}$ & $\begin{array}{l}\text { ES MOD } \\
\text { NUC grade }\end{array}$ & $\begin{array}{l}\text { Tumor growth } \\
\text { pattern }\end{array}$ & $\begin{array}{l}\text { Inflammation grade in } \\
\text { background liver (Ishak scores): } \\
\text { interface, lobular, portal }\end{array}$ & $\begin{array}{c}\text { Fibrosis stage in } \\
\text { background liver } \\
\text { (Ishak scores out of 6) }\end{array}$ & Steatosis $^{\mathrm{d}}$ \\
\hline 1 & 4.7 & $\mathrm{~T} 2$ & G2 & 2 & Solid & $3,1,3$ & 2 & 0 \\
\hline 2 & 2.7 & $\mathrm{~T} 1$ & G1 & 1 & Solid & $1,2,2$ & 3 & 0 \\
\hline 3 & 4.5 & $\mathrm{~T} 1$ & G2 & 1 & Pseudoglandular & $2,1,2$ & 2 & 0 \\
\hline 4 & 3.5 & $\mathrm{~T} 1$ & All necrotic & All necrotic & All necrotic & $1,1,2$ & 2 & 0 \\
\hline 5 & $2.8 ; 1.4$ & $\mathrm{~T} 2$ & G1 & 2 & Pseudoglandular & $1,1,2$ & 1 & 1 \\
\hline 6 & 3.5 & $\mathrm{~T} 1$ & $\mathrm{G} 2$ & 2 & Pseudoglandular & $1,1,2$ & 2 & 0 \\
\hline 7 & $4.5 ; 2.8 ; 2.0$ & $\mathrm{~T} 2$ & $\mathrm{G} 2$ & 4 & Solid & $1,1,2$ & $\begin{array}{l}\text { 2, also mild } \\
\text { pericellular fibrosis }\end{array}$ & 2 with mild SH \\
\hline 8 & $3.5 ; 2.7$ & $\mathrm{~T} 2$ & G1 & 3 & Solid & $2,1,3$ & 3 & 0 \\
\hline 9 & $\begin{array}{l}15 \text { with numerous } \\
\text { adjacent satellite nodules }\end{array}$ & $\mathrm{T} 3 \mathrm{~N} 1$ & $\mathrm{G} 2$ & 3 & $\begin{array}{l}\text { Pseudoglandular } \\
\text { and solid }\end{array}$ & $1,2,2$ & 3 & 0 \\
\hline 10 & 4.3 & $\mathrm{~T} 1$ & G3 & 4 & Solid & $1,1,3$ & 1 & 1 \\
\hline 11 & 4.2 & $\mathrm{~T} 2$ & $\mathrm{G} 2$ & 2 & Solid & $2,2,3$ & 3 & 1 \\
\hline 12 & $\begin{array}{l}26 \text { with numerous } \\
\text { adjacent satellite nodules }\end{array}$ & T3 & $\mathrm{G} 2$ & 3 & Pseudoglandular & $2,3,2$ & 2 & 1 \\
\hline 13 & $4.7 ; 1.1$ & $\mathrm{~T} 1$ & G2 & 3 & Pseudoglandular & $1,1,3$ & 3 & 2 \\
\hline 14 & $7.0 ; 2.2$ & T3 & $\mathrm{G} 2$ & 4 & Solid & $3,2,3$ & 1 & 0 \\
\hline 15 & 10.8 & $\mathrm{~T} 2$ & $\mathrm{G} 2$ & 2 & Solid & $2,3,2$ & 3 & \\
\hline 16 & 6.5 & T3 & $\mathrm{G} 2$ & 3 & Solid and pseudoglandular & $1,1,3$ & 1 & 0 \\
\hline 17 & $2 ; 3.5$ & $\mathrm{~T} 2$ & $\mathrm{G} 2$ & 3 & Solid & $2,1,2$ & 2 & 0 \\
\hline 18 & $\begin{array}{l}5 \text {, with numerous adjacent } \\
\text { satellite nodules }\end{array}$ & $\mathrm{T} 2$ & $\mathrm{G} 2$ & 3 & Pseudoglandular & $1,1,3$ & 2 & 0 \\
\hline
\end{tabular}

Abbreviations: ES, Edmonson-Steiner; SH, steatohepatitis.

${ }^{\mathrm{a}}$ AJCC (American Joint Committee on Cancer) tumor stage.

${ }^{\mathrm{b}}$ Hamilton and Lauri, 2000. ${ }^{12}$

${ }^{\mathrm{C}}$ Nzeako et al, 1995. ${ }^{11}$

${ }^{\mathrm{d}}$ Steatosis was scored as 0 ( 0 to $4 \%$ steatosis), 1 (5 to $30 \%$ steatosis), 2 (31 to $60 \%$ steatosis) and 3 (greater than $60 \%$ steatosis). 
interaction with the translational machinery and post-translational modifications systems. ${ }^{18}$ However, the mechanisms of HCV-induced hepatocellular carcinoma in non-cirrhotic livers remains unclear.

Besides the possible direct effects exerted by the HCV on the host genome, it is also plausible that hepatocellular carcinoma can develop in non-cirrhotic livers as a result of cycles of inflammation, necrosis and regeneration due to chronic hepatitis C-induced liver cell injury in the liver. Increased cell turnover in this setting of inflammation and oxidative DNA damage may facilitate the accumulation of genetic and epigenetic alterations, which include activation of cellular oncogenes and proliferative signaling pathways, telomerase activation, inactivation of tumor-suppressor genes and overexpression of growth and angiogenic factors. ${ }^{18}$

The hepatocellular carcinomas reported in this case series do not represent an unusual subtype of hepatocellular carcinoma: the hepatocellular carcinoma all had the typical clinical and histological characteristics. Sequence analysis found no exon 3 CTNNB1 ( $\beta$-catenin) mutations. Earlier studies suggested an association between $\beta$-catenin mutations and HCV-associated hepatocellular carcinoma ${ }^{19,20}$ and recent reports have also implicated the HCV core protein in the activation of the $\mathrm{Wnt} / \beta$-catenin pathway. ${ }^{21}$ The lack of $\beta$-catenin mutations in the 18 patients in this study suggests that alternative pathways exist, which warrant further investigation.

Aflatoxin exposure is known to play an important role in the development of hepatocellular carcinomas. ${ }^{22}$ In the current study, sequencing of exon 7 of TP53 showed no mutations in this recognized mutational hot spot for aflatoxin-associated hepatocellular carcinoma, ${ }^{23}$ providing evidence that exposure to aflatoxin-B1 did not contribute to the etiology of these carcinomas. Besides HCV infection, only one patient had a significant history of alcohol use and iron overload. The remaining patients did not have any other known risk factors for hepatocellular carcinoma other than chronic HCV infection.

Pathological examination of the background livers in the resection specimens showed that none of the cases had cirrhosis. However, several individuals did have advanced fibrosis with stage-3 or bridging fibrosis. In some of these cases, it is possible that individuals had more advanced fibrosis that has now regressed. Others have also reported cases of hepatocellular carcinoma arising in individuals who were long-term, HCV-sustained virological responders, some of whom did not have cirrhosis. ${ }^{24}$ Whether HCV-infected patients with bridging fibrosis, but not cirrhosis, should be offered screening for hepatocellular carcinoma is not clear. The point at which the risk of hepatocellular carcinoma starts to climb is unknown and transition to cirrhosis cannot always be accurately determined. However, the European Association for the Study of Liver Disease Single Topic Conference suggested that screening should be offered to HCV-infected patients with METAVIR stage-3 fibrosis, ${ }^{25}$ although the costefficacy of this recommendation has not been fully assessed.

Dysplastic nodules within the liver are a recognized pre-neoplastic lesion. ${ }^{26-29}$ Most dysplastic nodules are found in the setting of liver cirrhosis, but they may occasionally be seen in non-cirrhotic livers. ${ }^{30,31}$ No dysplastic nodules were identified in the background livers of these cases.

This study has several limitations, the principal one being the retrospective nature of the study. In part because of this, complete virological data in terms of hepatitis $\mathrm{C}$ viral loads and HCV genotypes were not available. In addition, as many individuals were primarily surgical referrals, details of prior antiviral therapy were largely not available. It is also recognized that paraffin-embedded tissues are not as sensitive as frozen tissues for excluding occult hepatitis B infection. Despite these limitations, this cohort is important in showing that hepatocellular carcinomas can arise in non-cirrhotic livers in individuals with hepatocellular carcinoma.

In conclusion, this study shows that hepatocellular carcinoma can arise in livers with chronic hepatitis C infection without cirrhosis. These hepatocellular carcinomas had typical clinical and pathological features of hepatocellular carcinoma. There was no evidence of HBV infection and molecular studies provided no evidence for aflatoxin exposure. It is possible that established cirrhosis may have regressed in some cases, but the possibility that HCV infection and inflammation may be directly oncogeneic, cannot be excluded. Regardless of the mechanism, these findings highlight an important and previously under-recognized risk for hepatocellular carcinoma in HCV-infected individuals who do not have cirrhosis.

\section{Acknowledgement}

This work was supported by R01DK078686 (MT).

\section{Disclosure/conflict of interest}

The authors declare no conflict of interest

\section{References}

1 El-Serag HB, Mason AC. Rising incidence of hepatocellular carcinoma in the United States. N Engl J Med 1999;340:745-750.

2 Buendia MA. Hepatitis B viruses and hepatocellular carcinoma. Adv Cancer Res 1992;59:167-226.

3 Wang XW, Forrester K, Yeh H, et al. Hepatitis B virus X protein inhibits p53 sequence-specific DNA binding, transcriptional activity, and association with transcription factor ERCC3. Proc Natl Acad Sci USA 1994;91: 2230-2234. 
4 Degos F, Christidis C, Ganne-Carrie N, et al. Hepatitis C virus related cirrhosis: time to occurrence of hepatocellular carcinoma and death. Gut 2000;47:131-136.

5 Fattovich G, Giustina G, Degos F, et al. Morbidity and mortality in compensated cirrhosis type C: a retrospective follow-up study of 384 patients. Gastroenterology 1997;112:463-472.

6 Niederau C, Lange S, Heintges T, et al. Prognosis of chronic hepatitis $\mathrm{C}$ : results of a large, prospective cohort study. Hepatology 1998;28:1687-1695.

7 Evert M, Dombrowski F. [Hepatocellular carcinoma in the non-cirrhotic liver]. Pathologe 2008;29:47-52.

8 Armstrong GL, Wasley A, Simard EP, et al. The prevalence of hepatitis $\mathrm{C}$ virus infection in the United States, 1999 through 2002. Ann Intern Med 2006;144: 705-714.

9 Torbenson M, Thomas DL. Occult hepatitis B. Lancet Infect Dis 2002;2:479-486.

10 Katiyar S, Dash BC, Thakur V, et al. P53 tumor suppressor gene mutations in hepatocellular carcinoma patients in India. Cancer 2000;88:1565-1573.

11 Nzeako UC, Goodman ZD, Ishak KG. Comparison of tumor pathology with duration of survival of North American patients with hepatocellular carcinoma. Cancer 1995;76:579-588.

12 Hamilton SR, Lauri A, (ed). WHO Classification of Tumors. Pathology and Genetics of Tumors of the Digestive System. IARC Press: Lyon, 2000.

13 Greene FL, Page D, Fleming ID, et al (ed). AJCC Cancer Staging Handbook 6th edn. Springer-Verlag: New York, 2002.

14 Di Bisceglie AM, Lyra AC, Schwartz M, et al. Hepatitis C-related hepatocellular carcinoma in the United States: influence of ethnic status. Am J Gastroenterol 2003;98:2060-2063.

15 Sherman M. Hepatocellular carcinoma: epidemiology, risk factors, and screening. Semin Liver Dis 2005;25:143-154.

16 Feitelson MA, Lee J. Hepatitis B virus integration, fragile sites, and hepatocarcinogenesis. Cancer Lett 2007;252:157-170.

17 Kannangai R, Vivekanandan P, Netski D, et al. Liver enzyme flares and occult hepatitis B in persons with chronic hepatitis C infection. J Clin Virol 2007;39: 101-105.

18 Levrero M. Viral hepatitis and liver cancer: the case of hepatitis C. Oncogene 2006;25:3834-3847.

$19 \mathrm{Hsu}$ HC, Jeng YM, Mao TL, et al. Beta-catenin mutations are associated with a subset of low-stage hepatocellular carcinoma negative for hepatitis B virus and with favorable prognosis. Am J Pathol 2000;157: 763-770.

20 Huang H, Fujii H, Sankila A, et al. Beta-catenin mutations are frequent in human hepatocellular carcinomas associated with hepatitis $\mathrm{C}$ virus infection. Am J Pathol 1999;155:1795-1801.

21 Fukutomi T, Zhou Y, Kawai S, et al. Hepatitis C virus core protein stimulates hepatocyte growth: correlation with upregulation of wnt-1 expression. Hepatology 2005;41:1096-1105.

22 Hussain SP, Schwank J, Staib F, et al. TP53 mutations and hepatocellular carcinoma: insights into the etiology and pathogenesis of liver cancer. Oncogene 2007;26:2166-2176.

23 Hsu IC, Metcalf RA, Sun T, et al. Mutational hotspot in the p53 gene in human hepatocellular carcinomas. Nature 1991;350:427-428.

24 Scherzer TM, Reddy KR, Wrba F, et al. Hepatocellular carcinoma in long-term sustained virological responders following antiviral combination therapy for chronic hepatitis C. J Viral Hepat 2008;15:659-665.

25 Bruix J, Sherman M, Llovet JM, et al. Clinical management of hepatocellular carcinoma. Conclusions of the Barcelona-2000 EASL conference. European Association for the Study of the Liver. J Hepatol 2001;35: 421-430.

26 Eguchi A, Nakashima O, Okudaira S, et al. Adenomatous hyperplasia in the vicinity of small hepatocellular carcinoma. Hepatology 1992;15:843-848.

27 Furuya K, Nakamura M, Yamamoto Y, et al. Macroregenerative nodule of the liver. A clinicopathologic study of 345 autopsy cases of chronic liver disease. Cancer 1988;61:99-105.

28 Takayama T, Makuuchi M, Hirohashi S, et al. Malignant transformation of adenomatous hyperplasia to hepatocellular carcinoma. Lancet 1990;336: 1150-1153.

29 Terada T, Ueda K, Nakanuma Y. Histopathological and morphometric analysis of atypical adenomatous hyperplasia of human cirrhotic livers. Virchows Arch A Pathol Anat Histopathol 1993;422:381-388.

30 Hytiroglou P, Park YN, Krinsky G, et al. Hepatic precancerous lesions and small hepatocellular carcinoma. Gastroenterol Clin North Am 2007;36: 867-887, vii.

31 Libbrecht L, Desmet V, Roskams T. Preneoplastic lesions in human hepatocarcinogenesis. Liver Int $2005 ; 25: 16-27$. 